\title{
Molecular and Epigenetic Mechanism Regulating Hypothalamic Kiss 1 Gene Expression in Mammals
}

\author{
Yoshihisa Uenoyama ${ }^{a}$ Junko Tomikawa ${ }^{a}$ Naoko Inoue ${ }^{a}$ Teppei Goto ${ }^{a}$ \\ Shiori Minabe ${ }^{a}$ Nahoko leda $^{a}$ Sho Nakamurab ${ }^{b}$ Youki Watanabe $^{a}$ \\ Kana Ikegami ${ }^{a}$ Fuko Matsuda ${ }^{a}$ Satoshi Ohkura ${ }^{a}$ Kei-ichiro Maeda ${ }^{b}$ \\ Hiroko Tsukamura ${ }^{a}$ \\ ${ }^{a}$ Graduate School of Bioagricultural Sciences, Nagoya University, Nagoya, and ${ }^{b}$ Department of Veterinary \\ Medical Sciences, The University of Tokyo, Tokyo, Japan
}

\section{Key Words}

Estrogen · Gonadotropin-releasing hormone · GPR54 •

Kisspeptin · Luteinizing hormone · Puberty

\begin{abstract}
After the discovery of hypothalamic kisspeptin encoded by the Kiss 1 gene, the central mechanism regulating gonadotropin-releasing hormone (GnRH) secretion, and hence gonadotropin secretion, is gradually being unraveled. This has increased our understanding of the central mechanism regulating puberty and subsequent reproductive performance in mammals. Recently, emerging evidence has indicated the molecular and epigenetic mechanism regulating hypothalamic Kiss 1 gene expression. Here we compile data regarding DNA and histone modifications in the Kiss 1 promoter region and provide a hypothetic scheme of the molecular and epigenetic mechanism regulating Kiss 1 gene expression in two populations of hypothalamic kisspeptin neurons, which govern puberty and subsequent reproductive performance via $\mathrm{GnRH/gonadotropin} \mathrm{secretion.}$
\end{abstract}

\section{KARGER}

E-Mail karger@karger.com

www.karger.com/nen

\section{Introduction}

Proper regulation of gene expression in each cell type sharing the same genetic blueprint is controlled by the binding of different transcription factors and epigenetic modifications. The past decade has seen remarkable progress in our understanding of epigenetic regulation of gene expression in mammals during embryo development, in each cell type and at various disease states [15]. Generally, epigenetic modifications fall into two broad categories: DNA methylation and histone modifications. DNA methylation in cytosines of the CpG dinucleotides of the promoter region is perhaps the most extensively studied epigenetic modification in mammals and is generally linked to the repression of gene expression. DNA methylation is catalyzed by a family of DNA methyltransferases [6] and recruits methyl-CpG binding domain proteins in combination with histone deacetylases to transform chromatin to a repressive state [3]. On the other hand, posttranslational modifications of histone proteins such as lysine acetylation and methylation can lead to either gene activation or repression
(C) 2016 S. Karger AG, Basel

0028-3835/16/1036-0640\$39.50/0
Hiroko Tsukamura

Graduate School of Bioagricultural Sciences Nagoya University

Furo-cho, Chikusa-ku, Nagoya 464-8601 (Japan)

E-Mail htsukamura@ nagoya-u.jp 
[7]. Acetylation at lysines 9 and 14 of histone $\mathrm{H} 3$ protein (H3K9/14 acetylation) and trimethylation at lysine 4 of histone protein ( $\mathrm{H} 3 \mathrm{~K} 4$ trimethylation) are classified as activating and permissive histone modifications, respectively [7]. Those are catalyzed by histone acetyltransferases and histone methyltransferase, respectively, and both decrease the interaction between DNA and histones, and hence loosen the nucleosome structure, which is open to transcriptional factors [8]. Conversely, histone deacetylation by histone deacetylases and $\mathrm{H} 3 \mathrm{~K} 9 / 27$ trimethylation leads to a general repression of gene expression [7].

In the past few years, emerging evidence has indicated that epigenetic mechanisms regulate gene expression of hypothalamic neuropeptides controlling feeding and reproduction. A previous study showing epigenetic regulation of the Pomc gene encoding proopiomelanocortin expression [9] demonstrated an inverse relationship between DNA methylation and Pomc gene expression, and a mechanism linking maternal undernutrition to obesity in the offspring. The epigenetic regulation of the Gnrh1 gene encoding gonadotropin-releasing hormone $(\mathrm{GnRH})$ expression was reviewed elsewhere by Kurian and Terasawa [10], who demonstrated an inverse relationship between DNA methylation and Gnrh1 gene expression during the peripubertal period. Likewise, understanding of the epigenetic regulation of the Kiss 1 gene encoding kisspeptin (initially named metastin) expression has become increasingly clear [11-14].

This review focuses on the recent progress in our understanding of the molecular and epigenetic mechanisms regulating Kiss1 gene expression in the rodent hypothalamus during the estrous cycle and at the time of puberty onset. Estrogenic regulation of hypothalamic Kiss1 gene expression and its interaction with histone modifications will be the main topics discussed. The epigenetic contribution to the sexual dimorphism of Kiss 1 gene expression in rodents will also be discussed.

\section{Kiss 1 Gene Expression in Two Populations of Hypothalamic Kisspeptin Neurons and the Role of Estrogen Signaling}

Accumulating evidence indicates that kisspeptin neurons are located in two hypothalamic regions and play a critical role as a master regulator of pulsatile and surgemode GnRH secretion in all mammalian species examined to date [15-24]. Cyclic changes and the estrogenic regulation of hypothalamic Kiss 1 gene expression are well demonstrated in the mammalian hypothalamus, including rodents $[15,16,25]$ and sheep [26-28]. Kiss 1 gene expression is high at proestrus and is positively controlled by estrogen in the anteroventral periventricular nucleus (AVPV) and periventricular nucleus $(\mathrm{PeN})$ continuum (also known as the rostral periventricular area of the third ventricle) in rodents $[15,16]$. On the other hand, Kiss 1 gene expression in the arcuate nucleus (ARC) is high at diestrus and is negatively controlled by estrogen in rodents $[15,16,25]$. Both populations of kisspeptin neurons express estrogen receptor- $\alpha(\mathrm{ER} \alpha)[15,16,25,29]$. ER $\alpha$ knockout mice failed to duplicate those estrogen-dependent changes in Kiss 1 gene expression in both the AVPV and the ARC, whereas ER $\beta$ knockout mice did [15]. These findings suggest that estrogen-ER $\alpha$ signaling bidirectionally controls Kiss 1 gene expression in a brain region-specific manner and raise the following question: how does estradiol-ERa signaling bidirectionally control Kiss 1 gene expression in the AVPV and ARC?

Classic estrogen response element (ERE)-dependent and non-classic ERE-independent signaling pathways provide a clue to understanding the bidirectional regulation of Kiss 1 gene expression by estrogen. Jameson and colleagues [30] generated a mutated ERa lacking the DNA binding capacity to the ERE and demonstrated that estradiol exerts opposite effects on the classic ERE-dependent and non-classic ERE-independent signaling pathways: namely, estradiol stimulated ERE reporter expression via the interaction of wild-type ERa and suppressed AP-1 reporter expression via the interaction of mutated ER $\alpha$ as well as wild-type ER $\alpha$ [30]. In addition, $\mathrm{NF}-\kappa \mathrm{B}$ and Sp1, as well as Ap-1, reportedly interact with wild-type $\mathrm{ER} \alpha$ and inhibit their response element-driven reporter expression [31-33]. These findings suggest that the estrogen-ER $\alpha$ complex exerts a bidirectional influence on gene expression via ERE-dependent and -independent pathways; the latter transcriptional factors play a role as a DNA tethering partner or corepressor. Using non-classic ERa knock-in (NERKI) mice carrying mutated ERa, Gottsch et al. [34] demonstrated that estradiol failed to exert a positive influence on Kiss 1 gene expression in the AVPV, whereas estradiol successfully exerted a negative influence on Kiss1 gene expression in the ARC. In addition, Huijbregts and de Roux [35] demonstrated that estradiol suppressed Kiss1 promoter activity in a breast cancer cell line bearing luciferase reporter conjugated with the proximal promoter region of human KISS1 gene devoid of ERE. These in vivo and in vitro studies suggest that two separate ERE-dependent and ERE-independent pathways are responsible for estrogenic regula- 
tion of Kiss1 gene expression in the AVPV and ARC, respectively: estradiol-bound ERa seems to directly bind to the ERE of the Kiss 1 promoter region and then upregulates Kiss 1 gene expression in the AVPV, whereas estradiol-bound ERa seems to bind to the non-ERE response element viainteraction with other transcriptional factor(s) and then downregulates Kiss1 gene expression in the ARC. The question of which transcriptional factor(s), in combination with ERa, play(s) a critical role in estrogenic suppression of ARC Kiss 1 gene expression remains to be answered.

\section{Epigenetic Mechanism of Estrogenic Regulation of Kiss1 Gene Expression}

Analyses of the histone modulation of the Kiss 1 promoter region provide a clue to understanding the region-specific pattern of hypothalamic Kiss1 gene expression. Tomikawa et al. [11] showed that H3K9/14 acetylation, an activating histone $\mathrm{H} 3$ modification, in the Kiss 1 promoter region is closely associated with an increase in Kiss 1 gene expression in both the AVPV and the ARC of mice. Specifically, histone H3K9/14 acetylation and ERa binding in the AVPV Kiss1 promoter region were induced by estradiol and were positively associated with an increase in Kiss 1 gene expression in this nucleus. Furthermore, histone deacetylation inhibitor induced Kiss 1 expression in murine hypothalamic cell lines in vitro [11]. These findings suggest that histone H3K9/14 acetylation plays a critical role in inducing AVPV Kiss 1 gene expression at proestrus in mice. Indeed, the levels of histone $\mathrm{H} 3 \mathrm{~K} 9 / 14$ acetylation in the Kiss 1 promoter region are low at diestrus but increase at proestrus in the AVPV in mice. Estradiol also enhanced formation of the chromatin loop between the promoter and $3^{\prime}$ downstream regions of the Kiss 1 gene, suggesting that the $3^{\prime}$ downstream region of the Kiss1 gene plays a key role in regulating Kiss1 gene expression as an enhancer in the AVPV. Taken in the light of the NERKI mice described previously [34] and previous studies showing mechanisms of estradiol-induced histone acetylation [36, 37], it is likely that the estrogen-ERa complex on the ERE of the Kiss 1 promoter region induces histone acetylation of the Kiss1 promoter region via recruitment of histone acetyltransferases and/or reduction of histone deacetylases, and that, subsequently, the chromatin loop between the promoter and $3^{\prime}$ downstream regions of the Kiss 1 gene seems to be formed. This is a hypothetical scenario, and further studies are needed to clarify the molecular cascade controlling estradiol-induced AVPV Kiss 1 gene expression.

In contrast with the AVPV, histone $\mathrm{H} 3 \mathrm{~K} 9 / 14$ acetylation in the ARC Kiss1 promoter was increased by ovariectomy and reduced by estradiol treatment in mice [11], indicating that histone $\mathrm{H} 3 \mathrm{~K} 9 / 14$ acetylation of the Kiss 1 promoter is positively associated with Kiss 1 gene expression in the ARC in the absence of estrogen. Goto et al. [14] found ARC-specific chromatin loop formation between the promoter region and the $5^{\prime}$ upstream region of the Kiss 1 gene, suggesting that the $5^{\prime}$ upstream region of the Kiss 1 gene plays a key role in upregulating Kiss 1 gene expression as an enhancer in the ARC. This study also showed a binding of unoccupied ERa and putative transcriptional factor binding sites in the ARC-specific putative enhancer region of the Kiss 1 locus. The molecular mechanism regulating histone acetylation and chromatin loop formation of the ARC Kiss1 gene in the absence of estrogen should be investigated in the future. It should be noted that either unoccupied or occupied ERa may be unnecessary for ARC Kiss1 gene expression, because ARC Kiss 1 gene expression in ERa knockout mice was largely higher than in wild-type controls [15].

The hypothesis that region-specific enhancers of the Kiss 1 gene are involved in the induction of Kiss 1 gene expression in the AVPV and ARC is supported by the results of in vivo reporter assays using Kiss1-GFP reporter transgenic mice. The assay revealed that the $3^{\prime}$ downstream region of the Kiss 1 locus contributes to induction of estrogen-induced AVPV Kiss1 gene expression [11], while the $5^{\prime}$ upstream region of the Kiss 1 locus is conducive to ARC Kiss1 gene expression [14]. More specifically, chromatin loop formation between the Kiss1 promoter region and the $3^{\prime}$ downstream region in the AVPV or the $5^{\prime}$ upstream region in the ARC, respectively, may act as a switch, which could turn on Kiss1 gene expression. Figure 1a shows schematic illustrations of a putative mechanism involved in estrogen-induced AVPV Kiss1 gene expression: the localization of the AVPV-specific enhancer of the Kiss1 gene as well as the formation of the chromatin loop between the Kiss1 promoter region and the $3^{\prime}$ downstream region in the AVPV in the presence of estrogen. On the other hand, figure $1 \mathrm{~b}$ demonstrates a possible mechanism for ARC Kiss1 gene expression in the absence of estrogen: an ARC-specific enhancer located in the $5^{\prime}$ upstream regions of the Kiss 1 gene may form multiple chromatin loops with the Kiss1 promoter in the ARC.

Chromatin looping has been known to play a crucial role in gene repression as well as expression [38]. Tomi- 
kawa et al. [11] showed that estrogen enhanced multiple chromatin loop formation between the Kiss 1 promoter region and the $3^{\prime}$ downstream region in the ARC. It is, thus, tempting to speculate that estrogen-induced multiple chromatin loop formation may contribute to the estrogen-negative feedback action on ARC Kiss 1 gene expression (fig. 1b). Taken together with the results from NERKI mice, an ERE-independent pathway such as interaction of c-Jun and ERa would induce such ARC-specific multiple chromatin looping in the presence of estrogen. Further studies also need to clarify this issue.

\section{Role of Epigenetic Silencing for Pubertal Changes in ARC Kiss 1 Gene Expression and GnRH Secretion}

In mammals, sexual maturation at the onset of puberty is considered to be timed by an increase in $\mathrm{GnRH} /$ gonadotropin secretion. The central mechanism regulating pubertal changes in GnRH secretion has been extensively studied. As Ojeda and colleagues reviewed elsewhere $[39,40]$, pubertal changes in GnRH secretion depend on both stimulatory and inhibitory inputs from neurons and glial cells. Kisspeptin is now considered a powerful stimulator of the pubertal increase in GnRH/ gonadotropin secretion in mammals, because pubertal failure is known to be caused by loss-of-function mutations of the KISS1 gene - as well as its cognate receptor, the GPR54 gene - in human [41-43] and rodent models [24, 42, 44-49]. Also, a pubertal increase in Kiss1 gene expression was evident in both the AVPV and the ARC in rodents $[17,50,51]$. In particular, ARC kisspeptin neurons seem to be responsible for the pubertal increase in $\mathrm{GnRH}$ /gonadotropin secretion, because ovariectomy increased ARC Kiss 1 gene expression along with an increase in luteinizing hormone (LH) pulses, and estradiol replacement strongly suppressed them in prepubertal rats [50]. A study by Mayer et al. [52] showing that kisspeptin neuron-specific ERa knockout mice exhibited an advanced puberty onset suggests that prepubertal suppression of GnRH/LH secretion is mainly due to a direct action of estrogen on ARC Kiss1 gene expression. This result is consistent with our recent results showing that an estrogen microimplant in the ARC suppressed pulsatile LH secretion in prepubertal rats [53]. It should be noted that estradiol seems to exert a potent inhibitory effect on ARC Kiss1 gene expression via both direct and indirect pathways. Our recent study demonstrated that the medial preoptic area is also involved in estrogen-in-

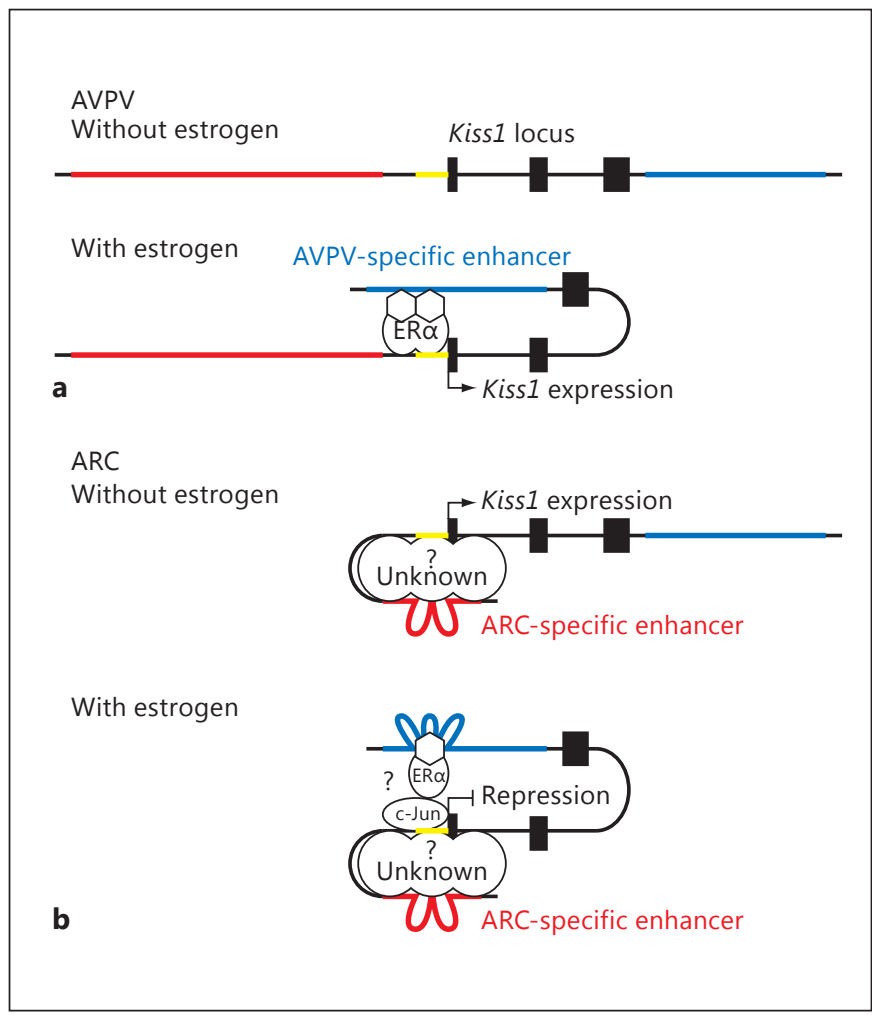

Fig. 1. Schematic illustration indicating the localization of regionspecific enhancers of the murine Kiss1 gene and formation of the chromatin loop between the Kiss 1 promoter region and enhancers. The solid boxes and red, blue, and yellow lines indicate three exons, the ARC-specific enhancer, the AVPV-specific enhancer, and the promoter region of the murine Kiss 1 locus, respectively. a The estrogen-ERa complex seems to play a critical role in chromatin loop formation between the Kiss 1 promoter region and the $3^{\prime}$ downstream region in the AVPV via the ERE-dependent pathway. b In the absence of estrogen, unknown transcriptional factors may induce chromatin loop formation between the Kiss 1 promoter region and the $5^{\prime}$ upstream region in the ARC. In the presence of estrogen, the $3^{\prime}$ downstream region of the Kiss 1 locus may serve as a repressor of the Kiss 1 gene via the ERE-independent pathway.

duced suppression of LH pulses in prepubertal rats [53], suggesting that estrogen-responsive neurons in the preoptic area contribute the prepubertal suppression of GnRH/LH secretion.

Ojeda and colleagues [12] demonstrated that polycomb epigenetic silencing is responsible for the pubertal changes in ARC Kiss 1 gene expression. Their chromatin immunoprecipitation assay showed a pubertal decrease in the binding of EED, a component of polycomb repressive complex 2 [54], in the Kiss 1 promoter region, and overexpression of EED resulted in suppression of Kiss 1 
gene expression and subsequent $\mathrm{GnRH}$ secretion in rats. These results suggest that the polycomb repressive complex 2 plays a critical role in suppressing ARC Kiss 1 gene expression and, hence, GnRH/gonadotropin secretion before the onset of puberty. It is well known that the polycomb repressive complex 2 exerts histone methyltransferase activity, resulting in histone $\mathrm{H} 3 \mathrm{~K} 27$ trimethylation, an inhibiting histone $\mathrm{H} 3$ modification [55]. Indeed, Lomniczi et al. [12] showed that in rats, H3K27 trimethylation in the Kiss1 promoter region decreased at the first proestrus, as opposed to the prepubertal period. They also demonstrated that increases in two activating histone $\mathrm{H} 3$ modifications (H3K4 trimethylation and $\mathrm{H} 3 \mathrm{~K} 9 / 14$ acetylation) in the Kiss 1 promoter region preceded the decrease in $\mathrm{H} 3 \mathrm{~K} 27$ trimethylation at the onset of puberty in female rats. Taken together, the relief from polycomb silencing and activating histone $\mathrm{H} 3$ modifications may play critical roles in triggering Kiss 1 gene expression at the onset of puberty in rats.

Ojeda and colleagues [12] also demonstrated that intraperitoneal administration of 5-azacytidine, a DNA methyltransferase inhibitor, delayed puberty onset in rats and depressed the hypothalamic-pituitary axis. This interpretation was supported by findings that administration of kisspeptin, GnRH, or equine chorionic gonadotropin overrides the suppression of GnRH, LH, or estradiol secretion in 5-azacytidine-treated animals, respectively. The 5-azacytidine treatment suppressed methylation of $\mathrm{CpG}$ dinucleotides of the putative Kiss 1 promoter region (flanking region of the Kiss 1 transcriptional start site), suggesting that methylation of the putative Kiss 1 promoter region is required for the pubertal increase in Kiss 1 gene expression. In several cancer cells, an inverse relationship was found between DNA methylation in the CpG island of the putative KISS1 promoter and KISS1 gene expression [56, 57]. However, this inverse relationship may be absent, along with the disappearance of the CpG island in the putative Kiss 1 promoter, in rodents, as already pointed out elsewhere [58]. Indeed, bisulfite sequencing by our and other groups has revealed that the putative Kiss 1 promoter region appeared hypermethylated: Tomikawa et al. [11] showed that methylation levels were comparable between Kiss1-expressing cells obtained from the AVPV or ARC and non-Kiss1expressing cells obtained from the cerebral cortex; Kauffman and colleagues [13] demonstrated that methylation levels were greater in AVPV tissue obtained from females than males. Taken together, putative Kiss 1 promoter methylation may be required for proper Kiss 1 gene expression in the rodent hypothalamus. Kiss1 promoter methylation in the ARC seems to be established before the onset of puberty, since Ojeda and colleagues [12] showed that the methylation levels are comparable between pre- and postpubertal periods. A likely explanation is that Kiss 1 promoter methylation is established before birth, because medial basal hypothalamus Kiss1 gene expression was found during late embryonic development and was highest at 18.5 embryonic days in rats [59] and 16.5 embryonic days in mice $[60,61]$. It should be noted that bisulfite sequencing cannot discriminate methylcytosine from hydroxymethylcytosine, an intermediate in the demethylation of methylated CpG dinucleotides [62], suggesting that our and other previous studies may have overestimated Kiss 1 promoter methylation. A previous study [63] showed that several methyl-CpG binding proteins do not recognize hydroxymethylcytosine, suggesting that hydroxymethylcytosine may serve to displace those bindings and relieve transcription silencing. Further studies, thus, are warranted to analyze DNA methylation and hydroxymethylation in the Kiss 1 promoter region.

\section{Epigenetic Regulation of Sexual Dimorphic AVPV Kiss 1 Gene Expression}

Kauffman and colleagues [13] explored epigenetic contributions to sexually dimorphic AVPV Kiss 1 gene expression in mice. In rodents, a sex difference in AVPV kisspeptin neurons is responsible for the sex difference in the mechanism generating a GnRH/LH surge [17-19]. Sexual dimorphism in AVPV Kiss1 gene expression and $\mathrm{GnRH} /$ gonadotropin secretion seems to be caused by an organizational effect of estrogen converted from testicular androgen, because neonatal administration of estrogen or aromatizable androgen resulted in a reduction of AVPV Kiss1 gene expression and disruption of GnRH/ LH surge generation in female rats $[18,19,64]$. This consideration is also supported by the finding that neonatal castration preserves AVPV Kiss1 gene expression as well as an estradiol-induced $\mathrm{GnRH} / \mathrm{LH}$ surge in male rats [19, 64]. Recently, Kauffman and colleagues [13] examined the contribution of histone modification to Kiss 1 gene expression in mice and showed that neonatal administration of valproic acid, a histone deacetylase inhibitor [65], failed to override sex dimorphic AVPV Kiss1 gene expression. On the other hand, neonatal administration of valproic acid increased the number of AVPV kisspeptin neurons in both sexes [13], as is the case with Bax knockout mice [66]. Based on these results, it is suggested that 


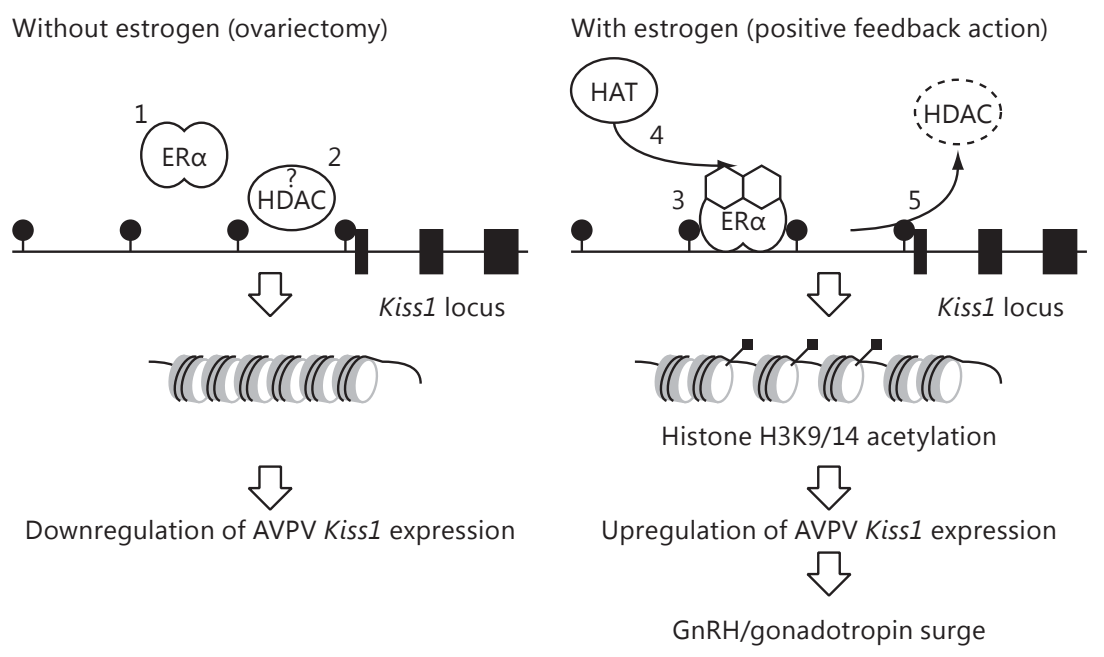

Fig. 2. Schematic illustration indicating a hypothetical scenario for the regulation of AVPV Kiss1 gene expression in the rodent hypothalamus in the absence or presence of estrogen in adults. Solid circles and boxes represent methylated $\mathrm{CpG}$ dinucleotides and exons of the Kiss1 gene, respectively. In the absence of estrogen, unoccupied ERa may not be capable of binding to the Kiss 1 promoter region (1), and histone deacetyltransferases (HDAC) may continuously suppress histone acetylation of the Kiss 1 promoter (2). At proestrus, the estrogen-ERa complex seems to bind to ERE in

histone acetylation and Bax-induced apoptosis contribute to the overall development of AVPV kisspeptin neurons in both sexes.

In the same study, Kauffman and colleagues [13] also examined DNA methylation in the whole region of the Kiss 1 locus and elaborated that $\mathrm{CpG}$ dinucleotides located in the promoter region and the first intron of the Kiss 1 gene appeared hypermethylated, and that the $\mathrm{CpG}$ island in exon 3 and its upstream region appeared hypomethylated in the AVPV. Interestingly, some of the CpG dinucleotides in the putative promoter and first intron of the Kiss 1 locus showed sexual dimorphism in terms of DNA methylation: DNA methylation levels were higher in females than in males, as was the case with AVPV Kiss1 gene expression in mice. Again, Kiss1 promoter methylation may be required for proper Kiss1 gene expression in the rodent brain, as opposed to suppression of gene expression. An in silico analysis identified putative repressor binding sites near some of the sexually dimorphic $\mathrm{CpG}$ dinucleotides of the Kiss1 promoter

region, suggesting that transcriptional repressors may contribute to the repression of AVPV/PeN Kiss1 gene expression in males [13]. DNA methylation of the Kiss1 gene body may be involved in AVPV/PeN Kiss 1 gene expression in a different manner, since emerging evidence indicates that gene body methylation has an impact on mRNA splicing [67].

\section{Possible Molecular and Epigenetic Mechanisms Regulating Kiss 1 Gene Expression, and Unanswered Questions}

A possible mechanism underlying estrogen-induced AVPV Kiss 1 gene expression and, hence, the GnRH/gonadotropin surge is illustrated in figure 2 . Based on the results currently available, we speculate that in the absence of estrogens, unoccupied ERa may not be capable of binding to the Kiss 1 promoter region (' 1 ' in fig. 2) and histone deacetyltransferases may continuously suppress 


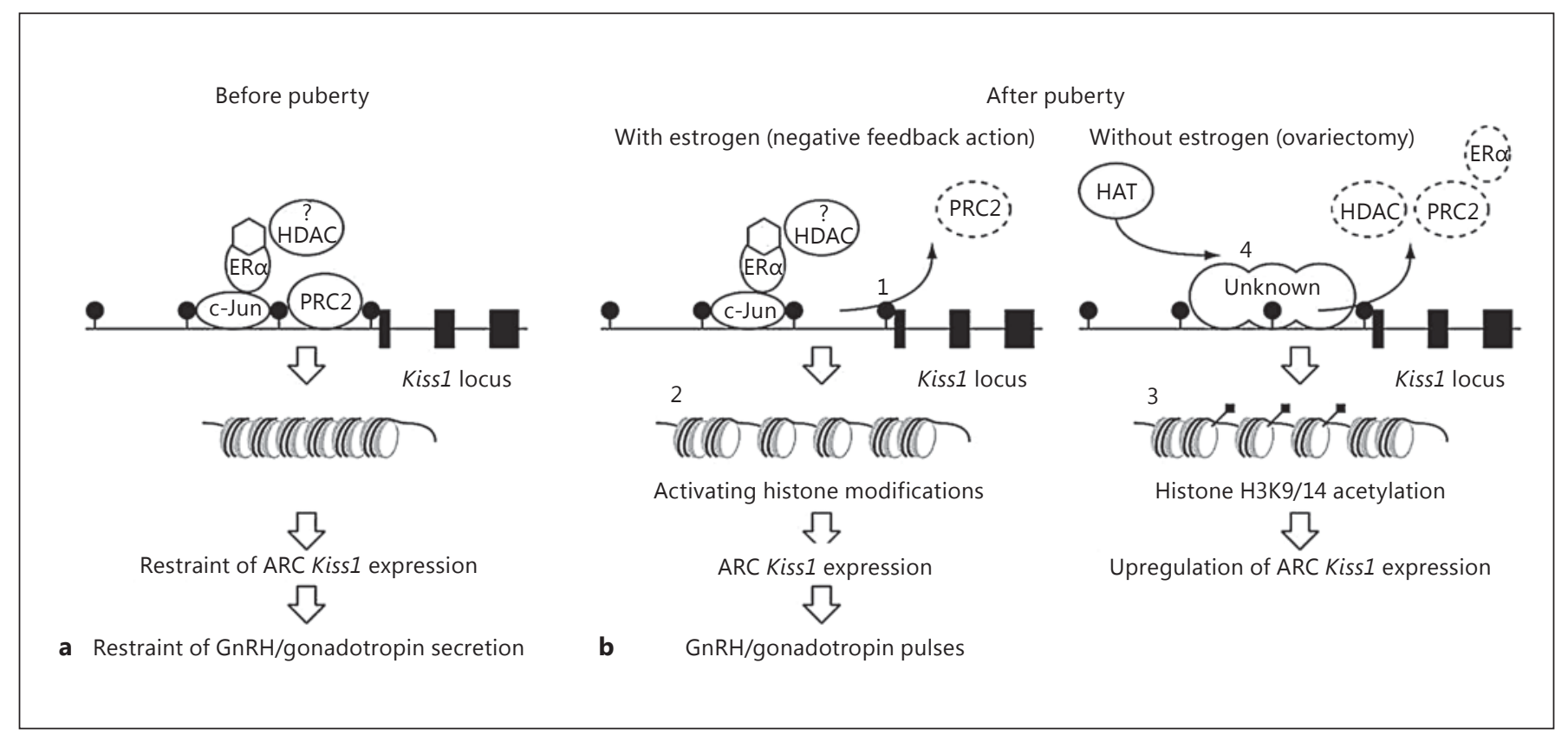

Fig. 3. Schematic illustration indicating a hypothetical scenario for the regulation of ARC Kiss1 gene expression in the rodent hypothalamus during pubertal transition. Solid circles and boxes represent methylated CpG dinucleotides and exons of the Kiss 1 gene, respectively. a At the prepubertal stage, polycomb repressive complex 2 (PRC2) seems to bind to the hypermethylated Kiss 1 promoter to repress ARC Kiss1 gene expression. The estrogen-ERa complex, interacting with c-Jun or some other transcription factor, may also play a role in prepubertal restraint of ARC Kiss 1 gene expression. The contribution of histone deacetyltransferases (HDAC) on the prepubertal restraint of Kiss 1 expression remains obscure, although the histone acetylation level of the Kiss 1 promoter region is likely low before puberty. b At the onset of puberty and thereaf-

histone acetylation of the Kiss1 promoter (' 2 ' in fig. 2). At the onset of puberty and thereafter, when the estrogen$\mathrm{ER} \alpha$ complex binds to the ERE in a hypermethylated Kiss 1 promoter region (' 3 ' in fig. 2), it may enhance histone $\mathrm{H} 3$ acetylation of the Kiss 1 promoter region via recruitment of histone acetyltransferases (' 4 ' in fig. 2) and reduction of histone deacetyltransferases (' 5 ' in fig. 2). We further speculate that this activating histone modification forms the chromatin loop between the promoter region and the $3^{\prime}$ downstream region of the Kiss 1 locus (fig. 1a), resulting in AVPV Kiss1 gene expression and, hence, induction of the preovulatory $\mathrm{GnRH} / g o-$ nadotropin surge in females (fig. 2). It is worth noting that the mechanism underlying AVPV Kiss1 gene expression seems conserved in males of nonrodent species. Our recent studies showed estrogen-induced activation of preoptic kisspeptin neurons (possibly equiva- ter, PRC2 would be dissociated from the Kiss 1 promoter (1) and may possibly enhance activating histone modification of the Kiss 1 promoter region, such as histone $\mathrm{H} 3 \mathrm{~K} 9 / 14$ acetylation and $\mathrm{H} 3 \mathrm{~K} 4$ trimethylation (2), even in the presence of estrogen. The activating histone modifications likely drive ARC Kiss 1 gene expression to enhance GnRH/gonadotropin pulses. Histone H3K9/14 acetylation is especially upregulated in the absence of estrogen (3), resulting in chromatin loop formation between the promoter and $5^{\prime}$ upstream regions of the Kiss 1 locus, further resulting in upregulation of Kiss 1 gene expression via unknown mechanisms (4). The mechanism regulating histone acetylation and chromatin loop formation of the Kiss 1 gene in the absence of estrogen also remains unknown. lent to AVPV kisspeptin neurons), which was accompanied by an LH surge in castrated male goats and monkeys [22, 23].

Likewise, a possible mechanism regulating ARC Kiss1 gene expression before and after the onset of puberty is illustrated in figure 3. We imagine that polycomb repressive complex 2 and perhaps the estrogenER a complex, interacting with some other transcriptional factors such as c-Jun, bind to the hypermethylated Kiss1 promoter to repress ARC Kiss1 gene expression until the onset of puberty (fig. 3a). At the onset of puberty, polycomb repressive complex 2 reportedly dissociates from the Kiss 1 promoter (' 1 ' in fig. $3 \mathrm{~b}$ ) and may possibly enhance histone $\mathrm{H} 3 \mathrm{~K} 9 / 14$ acetylation and $\mathrm{H} 3 \mathrm{~K} 4$ trimethylation in the Kiss 1 promoter region (' 2 ' in fig. 3b), resulting in Kiss 1 gene expression for stimulating $\mathrm{GnRH} /$ gonadotropin pulses. In particular, his- 
tone $\mathrm{H} 3 \mathrm{~K} 9 / 14$ acetylation (' 3 ' in fig. $3 \mathrm{~b}$ ) seems to form the chromatin loop between the promoter and $5^{\prime}$ upstream regions of the Kiss 1 locus in the absence of estrogen (fig. 1b), resulting in upregulation of ARC Kiss 1 gene expression via unknown mechanisms (' 4 ' in fig. 3b). These are hypothetical scenarios, and further studies are needed to clarify the molecular and epigenetic cascades responsible for region-specific Kiss1 gene expression and regulation.

Overall, the recent studies have increased our understanding of molecular and epigenetic mechanisms regulating Kiss 1 gene expression in the rodent hypothalamus. There are still important unanswered questions. For instance, are there activating and inhibiting histone modifications other than histone $\mathrm{H} 3 \mathrm{~K} 9 / 14$ acetylation that are involved in estrogen-induced Kiss 1 gene expression in the AVPV? How does the estrogen-ERa complex decrease histone acetylation in the Kiss 1 promoter region as well as subsequent Kiss1 gene expression in the ARC? Does the estrogen-ERa complex control histone modifications of the Kiss 1 locus in the peripubertal period? How does the estrogen-ERa complex alter Kiss 1 promoter methylation in the prenatal period in males? Further detailed analyses are required to clarify the molecular and epigenetic mechanisms regulating Kiss 1 expression in the $\mathrm{AVPV}$ and ARC in the future.

\section{Acknowledgements}

This study was supported in part by a grant from the Research Program on Innovative Technologies for Animal Breeding, Reproduction, and Vaccine Development (REP 2002, to H.T.), by the Science and Technology Research Promotion Program for Agriculture, Forestry, Fisheries, and Food Industry (to H.T.), and by Grants-in-Aid from the Japan Society for the Promotion of Science (26252046 and 24380157, to H.T. and K.M., respectively).

\section{References}

$>1$ Goldberg AD, Allis CD, Bernstein E: Epigenetics: a landscape takes shape. Cell 2007; 128:635-638.

-2 Bernstein BE, Meissner A, Lander ES: The mammalian epigenome. Cell 2007;128:669681.

3 Jaenisch R, Bird A: Epigenetic regulation of gene expression: how the genome integrates intrinsic and environmental signals. Nat Genet 2003;33(suppl):245-254

4 Sharma S, Kelly TK, Jones PA: Epigenetics in cancer. Carcinogenesis 2010;31:27-36.

$\checkmark 5$ Elliott EN, Kaestner KH: Epigenetic regulation of the intestinal epithelium. Cell Mol Life Sci 2015;72:4139-4156.

6 Bestor TH: The DNA methyltransferases of mammals. Hum Mol Genet 2000;9:23952402.

7 Zhou VW, Goren A, Bernstein BE: Charting histone modifications and the functional organization of mammalian genomes. Nat Rev Genet 2011;12:7-18.

$>8$ Rice JC, Allis CD: Histone methylation versus histone acetylation: new insights into epigenetic regulation. Curr Opin Cell Biol 2001;13: 263-273.

9 Stevens A, Begum G, White A: Epigenetic changes in the hypothalamic pro-opiomelanocortin gene: a mechanism linking maternal undernutrition to obesity in the offspring? Eur J Pharmacol 2011;660:194-201.

$>10$ Kurian JR, Terasawa E: Epigenetic control of gonadotropin releasing hormone neurons. Front Endocrinol (Lausanne) 2013;4:61.
11 Tomikawa J, Uenoyama Y, Ozawa M, Fukanuma T, Takase K, Goto T, Abe H, Ieda N, Minabe S, Deura C, Inoue N, Sanbo M, Tomita K, Hirabayashi M, Tanaka S, Imamura T, Okamura H, Maeda KI, Tsukamura H: Epigenetic regulation of Kiss1 gene expression mediating estrogen-positive feedback action in the mouse brain. Proc Natl Acad Sci USA 2012;109:E1294-E1301.

12 Lomniczi A, Loche A, Castellano JM, Ronnekleiv OK, Bosch M, Kaidar G, Knoll JG, Wright H, Pfeifer GP, Ojeda SR: Epigenetic control of female puberty. Nat Neurosci 2013; 16:281-289.

$>13$ Semaan SJ, Dhamija S, Kim J, Ku EC, Kauffman AS: Assessment of epigenetic contributions to sexually-dimorphic Kiss 1 expression in the anteroventral periventricular nucleus of mice. Endocrinology 2012;153:1875-1886.

14 Goto T, Tomikawa J, Ikegami K, Minabe S, Abe H, Fukanuma T, Imamura T, Takase K, Sanbo M, Tomita K, Hirabayashi M, Maeda KI, Tsukamura H, Uenoyama Y: Identification of hypothalamic arcuate nucleus-specific enhancer region of Kiss 1 gene in mice. Mol Endocrinol 2015;29:121-129.

15 Smith JT, Cunningham MJ, Rissman EF, Clifton DK, Steiner RA: Regulation of Kiss1 gene expression in the brain of the female mouse. Endocrinology 2005;146:3686-3692.
16 Adachi S, Yamada S, Takatsu Y, Matsui H, Kinoshita M, Takase K, Sugiura H, Ohtaki T, Matsumoto H, Uenoyama Y, Tsukamura H, Inoue $\mathrm{K}$, Maeda KI: Involvement of anteroventral periventricular metastin/kisspeptin neurons in estrogen positive feedback action on luteinizing hormone release in female rats. J Reprod Dev 2007;53:367-378.

17 Clarkson J, Herbison AE: Postnatal development of kisspeptin neurons in mouse hypothalamus; sexual dimorphism and projections to gonadotropin-releasing hormone neurons. Endocrinology 2006; 147:5817-5825.

18 Kauffman AS, Gottsch ML, Roa J, Byquist AC, Crown A, Clifton DK, Hoffman GE, Steiner RA, Tena-Sempere M: Sexual differentiation of Kiss 1 gene expression in the brain of the rat. Endocrinology 2007;148:1774-1783.

19 Homma T, Sakakibara M, Yamada S, Kinoshita M, Iwata K, Tomikawa J, Kanazawa T, Matsui $H$, Takatsu Y, Ohtaki T, Matsumoto H, Uenoyama Y, Maeda KI, Tsukamura H: Significance of neonatal testicular sex steroids to defeminize anteroventral periventricular kisspeptin neurons and the GnRH/LH surge system in male rats. Biol Reprod 2009;81:12161225.

20 Tomikawa J, Homma T, Tajima S, Shibata T, Inamoto Y, Takase K, Inoue N, Ohkura S, Uenoyama Y, Maeda KI, Tsukamura H: Molecular characterization and estrogen regulation of hypothalamic KISS1 gene in the pig. Biol Reprod 2010;82:313-319. 
-21 Steyn FJ, Wan Y, Clarkson J, Veldhuis JD, Herbison AE, Chen C: Development of a methodology for and assessment of pulsatile luteinizing hormone secretion in juvenile and adult male mice. Endocrinology 2013;154: 4939-4945.

22 Watanabe Y, Uenoyama Y, Suzuki J, Takase K, Suetomi Y, Ohkura S, Inoue N, Maeda KI, Tsukamura H: Oestrogen-induced activation of preoptic kisspeptin neurones may be involved in the luteinizing hormone surge in male and female Japanese monkeys. J Neuroendocrinol 2014;26:909-917.

23 Matsuda F, Nakatsukasa K, Suetomi Y, Naniwa $\mathrm{Y}$, Ito $\mathrm{D}$, Inoue $\mathrm{N}$, Wakabayashi $\mathrm{Y}$, Okamura H, Maeda KI, Uenoyama Y, Tsukamura $\mathrm{H}$, Ohkura S: The LH surge-generating system is functional in male goats as in females: involvement of kisspeptin neurones in the medial preoptic area. J Neuroendocrinol 2014;27:57-65.

-24 Uenoyama Y, Nakamura S, Hayakawa Y, Ikegami K, Watanabe $\mathrm{Y}$, Deura $\mathrm{C}$, Minabe S, Tomikawa J, Goto T, Ieda N, Inoue N, Sanbo M, Tamura C, Hirabayashi M, Maeda KI, Tsukamura H: Lack of pulse and surge modes and glutamatergic stimulation of LH release in Kiss 1 knockout rats. J Neuroendocrinol 2015;27:187-197.

25 Kinoshita M, Tsukamura H, Adachi S, Matsui H, Uenoyama Y, Iwata K, Yamada S, Inoue K, Ohtaki T, Matsumoto H, Maeda K: Involvement of central metastin in the regulation of preovulatory luteinizing hormone surge and estrous cyclicity in female rats. Endocrinology 2005; 146:4431-4436.

26 Estrada KM, Clay CM, Pompolo S, Smith JT, Clarke IJ: Elevated KiSS-1 expression in the arcuate nucleus prior to the cyclic preovulatory gonadotrophin-releasing hormone/lutenising [sic!] hormone surge in the ewe suggests a stimulatory role for kisspeptin in oestrogen-positive feedback. J Neuroendocrinol 2006; 18:806-809.

27 Smith JT, Clay CM, Caraty A, Clarke IJ: KiSS1 messenger ribonucleic acid expression in the hypothalamus of the ewe is regulated by sex steroids and season. Endocrinology 2007; 148:1150-1157.

28 Smith JT, Li Q, Pereira A, Clarke IJ: Kisspeptin neurons in the ovine arcuate nucleus and preoptic area are involved in the preovulatory luteinizing hormone surge. Endocrinology 2009;150:5530-5538.

-29 Clarkson J, d'Anglemont de Tassigny X, Moreno AS, Colledge WH, Herbison AE: Kisspeptin-GPR54 signaling is essential for preovulatory gonadotropin-releasing hormone neuron activation and the luteinizing hormone surge. J Neurosci 2008;28:86918697.

30 Jakacka M, Ito M, Weiss J, Chien PY, Gehm $\mathrm{BD}$, Jameson JL: Estrogen receptor binding to DNA is not required for its activity through the nonclassical AP1 pathway. J Biol Chem 2001;276:13615-13621.
31 Ray A, Prefontaine KE, Ray P: Down-modulation of interleukin- 6 gene expression by $17 \beta$-estradiol in the absence of high affinity DNA binding by the estrogen receptor. J Biol Chem 1994;269:12940-12946.

32 Stein B, Yang MX: Repression of the interleukin- 6 promoter by estrogen receptor is mediated by NF-kappa B and C/EBP beta. Mol Cell Biol 1995;15:4971-4979.

33 Safe S: Transcriptional activation of genes by $17 \beta$-estradiol through estrogen receptor-Sp1 interactions. Vitam Horm 2001;62:231-252.

34 Gottsch ML, Navarro VM, Zhao Z, GlidewellKenney C, Weiss J, Jameson JL, Clifton DK, Levine JE, Steiner RA: Regulation of Kiss1 and dynorphin gene expression in the murine brain by classical and nonclassical estrogen receptor pathways. J Neurosci 2009;29:93909395.

35 Huijbregts L, de Roux N: KISS1 is down-regulated by $17 \beta$-estradiol in MDA-MB-231 cells through a nonclassical mechanism and loss of ribonucleic acid polymerase II binding at the proximal promoter. Endocrinology 2010;151: 3764-3772.

36 Sun JM, Chen HY, Davie JR: Effect of estradiol on histone acetylation dynamics in human breast cancer cells. J Biol Chem 2001; 276:49435-49442.

37 Fortress AM, Kim J, Poole RL, Gould TJ, Frick KM: $17 \beta$-Estradiol regulates histone alterations associated with memory consolidation and increases $B d n f$ promoter acetylation in middle-aged female mice. Learn Mem 2014; 21:457-467.

38 Tiwari VK, McGarvey KM, Licchesi JD, Ohm JE, Herman JG, Schübeler D, Baylin SB: PcG proteins, DNA methylation, and gene repression by chromatin looping. PLoS Biol 2008;6: 2911-2927.

39 Ojeda SR, Lomniczi A, Mastronardi C, Heger S, Roth C, Parent AS, Matagne V, Mungenast AE: Minireview: the neuroendocrine regulation of puberty: is the time ripe for a systems biology approach? Endocrinology 2006;147: 1166-1174.

40 Lomniczi A, Wright H, Ojeda SR: Epigenetic regulation of female puberty. Front Neuroendocrinol 2014;36:90-107.

41 de Roux N, Genin E, Carel JC, Matsuda F, Chaussain JL, Milgrom E: Hypogonadotropic hypogonadism due to loss of function of the KiSS1-derived peptide receptor GPR54. Proc Natl Acad Sci USA 2003;100:10972-10976.

42 Seminara SB, Messager S, Chatzidaki EE, Thresher RR, Acierno JS Jr, Shagoury JK, BoAbbas Y, Kuohung W, Schwinof KM, Hendrick AG, Zahn D, Dixon J, Kaiser UB, Slaugenhaupt SA, Gusella JF, O'Rahilly S, Carlton MB, Crowley WF Jr, Aparicio SA, Colledge $\mathrm{WH}$ : The GPR54 gene as a regulator of puberty. N Engl J Med 2003;349:1614-1627.

43 Topaloglu AK, Tello JA, Kotan LD, Ozbek MN, Yilmaz MB, Erdogan S, Gurbuz F, Temiz F, Millar RP, Yuksel B: Inactivating KISS1 mutation and hypogonadotropic hypogonadism. N Engl J Med 2012;366:629-635.
44 Funes S, Hedrick JA, Vassileva G, Markowitz L, Abbondanzo S, Golovko A, Yang S, Monsma FJ, Gustafson EL: The KiSS-1 receptor GPR54 is essential for the development of the murine reproductive system. Biochem Biophys Res Commun 2003;312:1357-1363.

45 Messager S, Chatzidaki EE, Ma D, Hendrick AG, Zahn D, Dixon J, Thresher RR, Malinge I, Lomet D, Carlton MB, Colledge WH, Caraty A, Aparicio SA: Kisspeptin directly stimulates gonadotropin-releasing hormone release via $G$ protein-coupled receptor 54. Proc Natl Acad Sci USA 2005;102:1761-1766.

46 d'Anglemont de Tassigny X, Fagg LA, Dixon JP, Day K, Leitch HG, Hendrick AG, Zahn D, Franceschini I, Caraty A, Carlton MB, Aparicio SA, Colledge WH: Hypogonadotropic hypogonadism in mice lacking a functional Kiss 1 gene. Proc Natl Acad Sci USA 2007;104: 10714-10719.

47 Dungan HM, Gottsch ML, Zeng H, Gragerov A, Bergmann JE, Vassilatis DK, Clifton DK, Steiner RA: The role of kisspeptin-GPR54 signaling in the tonic regulation and surge release of gonadotropin-releasing hormone/ luteinizing hormone. J Neurosci 2007;27: 12088-12095.

48 Lapatto R, Pallais JC, Zhang D, Chan YM, Mahan A, Cerrato F, Le WW, Hoffman GE, Seminara SB: Kiss $1^{-/}$mice exhibit more variable hypogonadism than $G p r 54^{-/-}$mice. Endocrinology 2007;148:4927-4936.

49 Chan YM, Broder-Fingert S, Wong KM, Seminara SB: Kisspeptin/Gpr54-independent gonadotrophin-releasing hormone activity in Kiss 1 and Gpr54 mutant mice. J Neuroendocrinol 2009;21:1015-1023.

50 Takase K, Uenoyama Y, Inoue N, Matsui H, Yamada S, Shimizu M, Homma T, Tomikawa J, Kanda S, Matsumoto H, Oka Y, Tsukamura $\mathrm{H}$, Maeda KI: Possible role of oestrogen in pubertal increase of Kiss $1 /$ kisspeptin expression in discrete hypothalamic areas of female rats. J Neuroendocrinol 2009;21:527-537.

51 Semaan SJ, Kauffman AS: Daily successive changes in reproductive gene expression and neuronal activation in the brains of pubertal female mice. Mol Cell Endocrinol 2015;401: 84-97.

52 Mayer C, Acosta-Martinez M, Dubois SL, Wolfe A, Radovick S, Boehm U, Levine JE: Timing and completion of puberty in female mice depend on estrogen receptor alpha-signaling in kisspeptin neurons. Proc Natl Acad Sci USA 2010;107:22693-22698.

53 Uenoyama Y, Tanaka A, Takase K, Yamada S, Pheng V, Inoue N, Maeda KI, Tsukamura H: Central estrogen action sites involved in prepubertal restraint of pulsatile luteinizing hormone release in female rats. J Reprod Dev 2015;61:351-359.

54 Simon JA, Kingston RE: Mechanisms of polycomb gene silencing: knowns and unknowns. Nat Rev Mol Cell Biol 2009;10:697-708. 
55 Müller J, Verrijzer P: Biochemical mechanisms of gene regulation by polycomb group protein complexes. Curr Opin Genet Dev 2009;19:150-158.

-56 Cebrian V, Fierro M, Orenes-Piñero E, Grau L, Moya P, Ecke T, Alvarez M, Gil M, Algaba F, Bellmunt J, Cordon-Cardo C, Catto J, López-Beltrán A, Sánchez-Carbayo M: KISS1 methylation and expression as tumor stratification biomarkers and clinical outcome prognosticators for bladder cancer patients. Am J Pathol 2011;179:540-546.

57 Chen SQ, Chen ZH, Lin SY, Dai QB, Fu LX, Chen RQ: KISS1 methylation and expression as predictors of disease progression in colorectal cancer patients. World J Gastroenterol 2014;20:10071-10081.

-58 Semaan SJ, Kauffman AS: Emerging concepts on the epigenetic and transcriptional regulation of the Kiss 1 gene. Int J Dev Neurosci 2013;31:452-462.
59 Desroziers E, Droguerre M, Bentsen AH, Robert V, Mikkelsen JD, Caraty A, Tillet Y, Duittoz A, Franceschini I: Embryonic development of kisspeptin neurones in rat. J Neuroendocrinol 2012;24:1284-1295.

60 Kumar D, Freese M, Drexler D, HermansBorgmeyer I, Marquardt A, Boehm U: Murine arcuate nucleus kisspeptin neurons communicate with GnRH neurons in utero. J Neurosci 2014;34:3756-3766.

61 Kumar D, Periasamy V, Freese M, Voigt A, Boehm U: In utero development of kisspeptin/GnRH neural circuitry in male mice. Endocrinology 2015;156:3084-3090.

62 Booth MJ, Branco MR, Ficz G, Oxley D, Krueger F, Reik W, Balasubramanian S: Quantitative sequencing of 5-methylcytosine and 5-hydroxymethylcytosine at single-base resolution. Science 2012;336:934-937.

63 Jin SG, Kadam S, Pfeifer GP: Examination of the specificity of DNA methylation profiling techniques towards 5-methylcytosine and 5-hydroxymethylcytosine. Nucleic Acids Res 2010;38:e125.
64 Sakakibara M, Deura C, Minabe S, Iwata Y, Uenoyama Y, Maeda KI, Tsukamura H: Different critical perinatal periods and hypothalamic sites of oestradiol action in the defeminization of LH surge and lordosis capacity in the rat. J Neuroendocrinol 2013;25:251-259.

65 Phiel CJ, Zhang F, Huang EY, Guenther MG, Lazar MA, Klein PS: Histone deacetylase is a direct target of valproic acid, a potent anticonvulsant, mood stabilizer, and teratogen. J Biol Chem 2001;276:36734-36741.

66 Semaan SJ, Murray EK, Poling MC, Dhamija S, Forger NG, Kauffman AS: BAX-dependent and BAX-independent regulation of Kiss1 neuron development in mice. Endocrinology 2010;151:5807-5817.

67 Jones PA: Functions of DNA methylation: islands, start sites, gene bodies and beyond. Nat Rev Genet 2012;13:484-492. 